\title{
CHEMICAL RESISTANCE OF BIOPOLYMERS BASED ON THE EPOXY RESIN MODIFIED WITH EPOXIDISED AND CYCLOCARBONATED SOYBEAN OILS Olha Purikova $^{1}$, Larisa Gorbach ${ }^{2}$, Oleksandr Brovko ${ }^{3}$
}

1. Department of Physical Chemistry of Polymers, Institute of Macromolecular Chemistry of the National Academy of Sciences of Ukraine, UKRAINE, Kyiv, Kharkivske shosse 48, E-mail: olhapurikova@gmail.com

2. Department of Physical Chemistry of Polymers, Institute of Macromolecular Chemistry of the National Academy of Sciences of Ukraine, UKRAINE, Kyiv, Kharkivske shosse 48, E-mail: gorbachla@ukr.net

3. Department of Physical Chemistry of Polymers, Institute of Macromolecular Chemistry of the National Academy of Sciences of Ukraine, UKRAINE, Kyiv, Kharkivske shosse 48, E-mail: brovko@ nas.gov.ua

Abstract - Environmentally friendly biocomposites based on ED-20 epoxy resin modified with reactive soybean oils functionalized with cyclocarbonate and epoxy groups were obtained with UP (mono(cyanoethyl) diethylene triamine) hardener. Influence of the curing mode on the water absorption and chemical resistance of the synthesized polymer materials was investigated.

Keywords - biocomposites; epoxy resin; epoxidized and cyclocarbonated soybean oil, chemical resistance, mechanical properties

\section{Introduction}

The attraction on the biocomposite materials (also known as green composites) due to the potential of being substitute to conventional materials has significantly increased nowadays because of awareness of environmental issues. Vegetable oils are typical sourses of biogenic modifiers; they are triacylglycerides and can be functionalised with reactive groups such as epoxy and cyclocarbonate and, hence, can be cross-linked to form rigid biocomposites [1-3]. Therefore, the objective of this work was to modify diglycidyl ether of bisphenol-A epoxy resin (ED-20) with functionalized SbO such as as cyclocarbonated soybean oils (SbOc) and mixture of epoxidized soybean oil and cyclocarbonated one ( $\mathrm{SbOm}$ ). The effect of modifier and curing mode on water sorption and chemical resistance of the synthesised samples has been studied and discussed.

\section{Experimental section}

Sample Preparation. Compositions of pristine as wel as modified ED-20 samples were synthesized with UP ((mono(cyanoethyl) diethylenetriamine)) hardener, its content for all samples was 20 wt.\% according to the monomer(s). Functionalised soybean oils, such as SbOc and SbOm were supplied by the group of researchers headed by Grishchenko V.K. and used as modifiers [4]. SbOm is a mixture of soybean oil functionalized with epoxy (12.5 wt.\%) and cyclocarbonate (24.6 wt.\%) groups, while SbOc contains soybean oil functionalized only with cyclocarbonate (27.03 wt.\%) groups. Mass fraction of functionalized SbO for all biocomposite samples was $10 \mathrm{wt} . \%$. The homogenized reaction mixture was poured into molds and cured under three different temperature regimes. The curing mode $\mathbf{I}$ was performed at $25{ }^{\circ} \mathrm{C}$ for 4 hours; curing mode II - 2 hours at $80^{\circ} \mathrm{C}, 7$ hours at $100{ }^{\circ} \mathrm{C}$; and curing mode III - 1 hour at 80 ${ }^{\circ} \mathrm{C}, 1$ hour at $100^{\circ} \mathrm{C}, 3$ hours at $120^{\circ} \mathrm{C}$, and 2 hours at $160^{\circ} \mathrm{C}$.

Characterization. Fourier transform infrared (FT-IR) spectra $\left(4000-400 \mathrm{~cm}^{-1}\right)$ of all synthesized materials were recorded on a TENSOR 37 spectrometer using $\mathrm{KBr}$ pellets. The chemical resistance of the synthesized samples to the action of aggressive media (water, 10 wt. $\% \mathrm{H}_{2} \mathrm{SO}_{4}$ and 10 wt. $\% \mathrm{NaOH}$ ) was determined in accordance with water absorption tests 
by ASTM D-570 - 98(2018) "Standard Test Method for Water Absorption of Plastics" and ISO 175:2010 "Plastics - Methods of test for the determination of the effects of immersion in liquid chemicals".

\section{Results and Discussion}

The chemical structures of the synthesizes samples were analyzed by FT-IR. It is observed that the characteristics peaks of both epoxy resin and functionalised $\mathrm{SbO}$ appear in all spectra of the initial reaction mixture. Characteristic bands of cyclocarbonates $\left(1798 \mathrm{~cm}^{-1}\right)$ and oxiran rings (913 and $830 \mathrm{~cm}^{-1}$ ) disappear after curing procedure. Biocomposite samples containing SbOc and $\mathrm{SbOm}$ revealed small band at $1713 \mathrm{~cm}^{-1}$ that corresponds to the $\mathrm{C}=\mathrm{O}$ group of hydroxyurethanes that confirm possible interaction between cyclocarbonate groups of $\mathrm{SbO}$ and amino-groups of UP hardener. This process can contribute to the grafting between epoxy matrix and soybean oil (Scheme 1) [5].

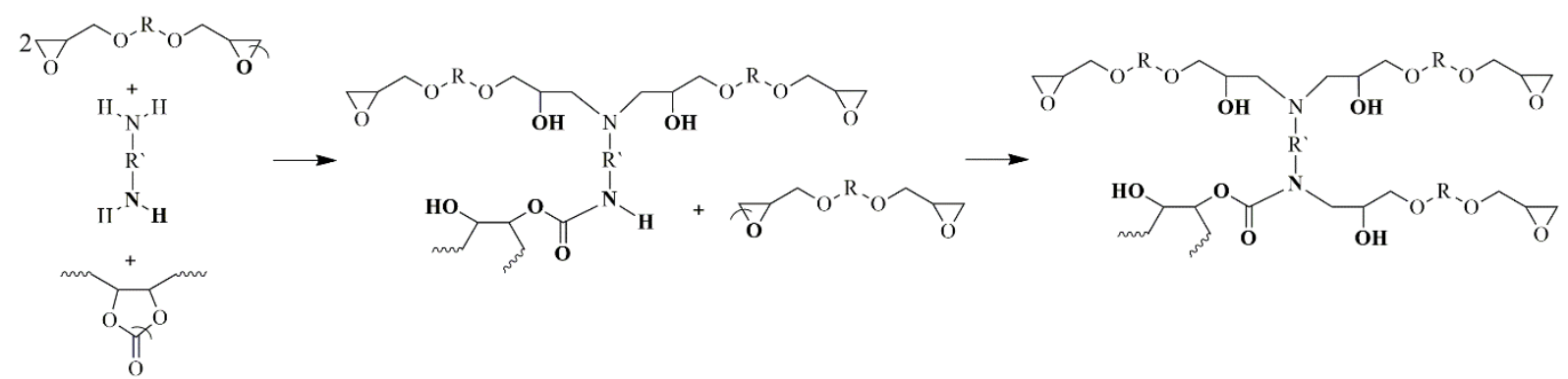

Scheme 1. Representation of interaction between epoxy resin, cyclocarbonate group of functionalized $\mathrm{SbO}$ and UP hardener as diamine

The character of the absorption curves indicates that all samples achieve sorption equilibrium without destruction in all aggressive media (Fig. 1). The water absorption degree in distilled water as well as in alkaline media of biocomposites increases negligibly compared to the corresponding samples of pristine ED-20 regardless of the type of modifier (Fig. 1.a and b). Thus, equilibrium water absorption $\left(W_{\max }\right)$ was in the range of $(1.0-1.8) \%$ for samples ED-20 with different curing mode, and $(2.0-2.8) \%$ and $(2.3-2.7) \%$ for samples ED-20/SbOc and $\mathrm{ED}-20 / \mathrm{SbOm}$ correspondently. It means that presense of functionalized $\mathrm{SbO}$ at the formation of epoxy network leads to slightly less dense netted structure formation. It should be noted that an increase in the curing temperature also has no significant effect on equilibrium water absorption in both water and alkaline medium for samples of pristine epoxy resin and biocomposites.
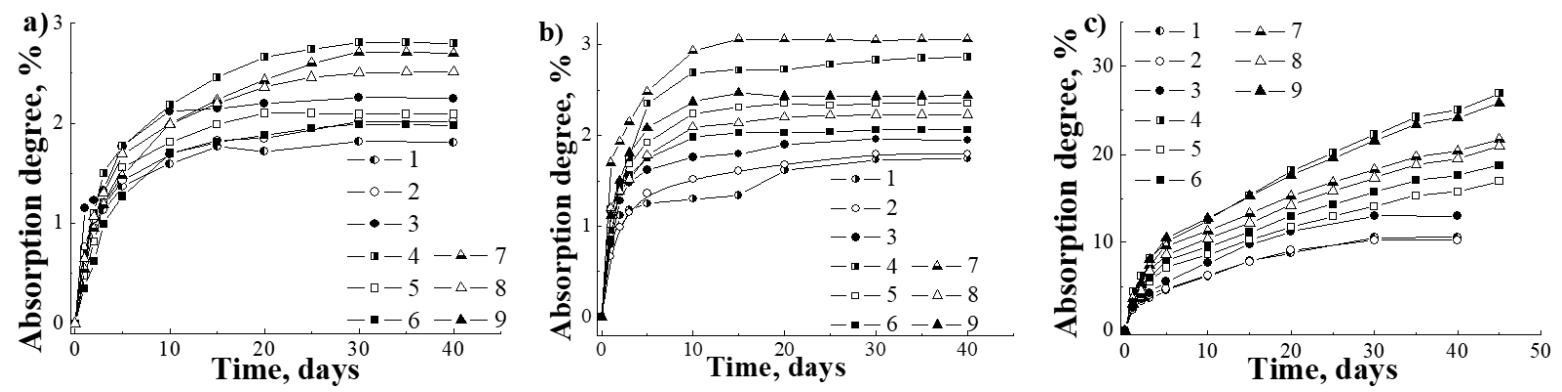

Fig.1. Water absorption curves (a) in distilled water, (b) in alkaline medium, (c) in acidic medium of epoxy polymers based on the ED-20 and their biocomposites made with UP hardener: 1, 2, 3 - pristine ED-20; 4, 5, 6-ED-20/SbOc; 7, 8, 9 - ED-20/SbOm. 1, 4, 7 - curing mode $\mathbf{I} ; 2,5,8$ - curing mode II; 3, 6, 9 - curing mode III. 
Investigation of chemical resistance in the acidic environment revealed that all samples had higher sorption capacity and thus lower chemical resistance (Fig. 1.c). For example, it increases by $\sim 6$ times for samples based on the pristine ED-20 and $\sim(7-9)$ times for biocomposites comparing to correspondent samples` resistane in the alkaline media. Samples of biocomposites showed, that their chemical resistance to acidic media is lower by $\sim 2$ times comparing with pristine ED-20 samples of corresponding curing mode.

It should be notified, that all synthesized samples after exposure to aggressive media did not detect any defects in the film surface such as cracking, delamination, discoloration, weight loss. Therefore, it can be concluded that destruction of the synthesized samples did not proceed.

\section{Conclusion}

In conclusion, environmentally friendly biocomposites based on ED-20 epoxy resin modified with reactive soybean oils functionalized with cyclocarbonate and epoxy groups were obtained with UP (mono(cyanoethyl) diethylene triamine) hardener. Possible chemical interaction between reactive groups of $\mathrm{SbO}$, epoxy resin and hardener was shown. Influence of the curing mode on the water absorption and chemical resistance of the synthesized polymer materials was investigated. Samples of biocomposites as well as unmodified samples revealed lower chemical resistance in acidic environment comparing to the water and alkali media. Addition of functionalized SbO to the epoxy matrix and chosen curing modes did not change chemical resistance to water and alkaline medium dramatically.

\section{References}

[1] Garipov, R. M., Sysoev, V. A., Mikheev, V. V., Zagidullin, A. I., Deberdeev, R. Y., Irzhak, V. I., \& Berlin, A. A. (2003). Reactivity of cyclocarbonate groups in modified epoxy-amine compositions. Doklady Physical Chemistry, 393 (1), 289-292. Kluwer Academic Publishers-Plenum Publishers.

[2] Gupta, A. P., Ahmad, S., \& Dev, A. (2011). Modification of novel bio-based resin-epoxidized soybean oil by conventional epoxy resin. Polymer Engineering \& Science, 51(6), 1087-1091. https://doi.org/10.1002/pen.21791

[3] Rokicki, G., \& Wojciechowski, C. (1990). Epoxy resin modified by aliphatic cyclic carbonates. Journal of applied polymer science, 41(3-4), 647-659. https://doi.org/10.1002/app.1990.070410315

[4] Barantsova A.V., Grishchenko V.K., Busko N.A., Falchenko Z.V., Shevchenko V.V. (2012). Synthesis and investigation of functionalized oils derivatives of different nature as biofuel raw materials, development of polymeric materials based on them. Catalysis and Petrochemistry, 21, 143-151. (In Ukr.)

[5] Cornille, A., Auvergne, R., Figovsky, O., Boutevin, B., \& Caillol, S. (2017). A perspective approach to sustainable routes for non-isocyanate polyurethanes. European Polymer Journal, 87, 535-552. https://doi.org/10.1016/j.eurpolymj.2016.11.027 